\section{ALUCINAÇÃO AUDITIVA: SINTOMA DE DOENÇA OU POSSIBILIDADE DE SER DO-ENTE?}

\section{Henrique Campagnollo D'Ávila Fernandes}

Mestre em Psicologia Clínica e Cultura Universidade de Brasília objective of this study is to problematize the traditional biomedical approach, through the contribution of thinkers and philosophers of different historical periods. In antiquity, the

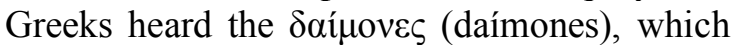
intermediated the communication between the gods and the men. The medievals understood the voices as demonic possession, witchcraft, heresy, or holiness. In Modernity the phenomenon received a pathological meaning, which restricted possibilities of being. One has to think about the fundamental question of philosophy as a condition of the possibility of opening the meaning of the phenomenon.

KEY WORDS: hallucination; mental disease; hearing voices; phenomenon; to be.

\section{RESUMO}

A alucinação auditiva é um fenômeno tematizado pelo homem ocidental desde a Antiguidade. Atualmente, ela é considerada sintoma de doença mental, pelo horizonte biomédico. Essa noção tem contribuído para o aumento não só de diagnósticos, como de medicalização e de sofrimento. Considerando essa questão, o objetivo deste estudo é problematizar o enfoque biomédico tradicional, por meio da contribuição de pensadores e filósofos de diferentes períodos históricos. Na Antiguidade, os gregos ouviam

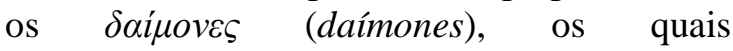
intermediavam a comunicação entre os deuses e os homens. Os medievais entenderam as vozes como possessão demoníaca, bruxaria, heresia, ou santidade. $\mathrm{Na}$ Modernidade o fenômeno recebeu um sentido patológico, que restringiu possibilidades de ser. Há que se pensar a questão fundamental da filosofia como condição de possibilidade de abertura de sentido do fenômeno.

PALAVRAS-CHAVE: alucinação; doença mental; audição de vozes; fenômeno; ser.

\section{ABSTRACT}

Auditory hallucination is a phenomenon thematized by Western man since antiquity. Currently, it is considered a symptom of mental illness, through the biomedical horizon. This notion has contributed to the increase not only of diagnoses, but also of medicalization and suffering. Considering this question, the
"Até hoje todo dia eu ouço vozes perturbadoras. Ontem lá em casa, ouvi uma voz lá depois do quarto da minha irmã falando assim "seu desgraçado!", como se eu estivesse frustrado mais uma vez querendo me internar". O relato de Eliezer ${ }^{1}$ diz respeito a um fenômeno entendido pelo horizonte biomédico moderno como alucinação auditiva, o qual é designado como uma percepção de vozes ou sons, sem a presença de um estímulo ou objeto (AMERICAN PSYCHIATRIC ASSOCIATION, 2014). O alucinado tem a impressão de que há outro ente (que não ele) falando. Em suma, é uma experiência de estar sendo comunicado por alguém que não esteja presente no campo material. quadros psicopatológicos, com maior

\footnotetext{
${ }^{1}$ Nome fictício, utilizado no intuito de resguardar o sigilo.
}

Tal fenômeno é associado a alguns 
destaque entre os transtornos psicóticos ${ }^{2}$. Em razão dessa associação, e pelo fato de a alucinação não ser um fenômeno relatado com tanta frequência, criou-se um estigma social muito forte em torno dela, de modo que o alucinado é visto como louco, e que, portanto, deve procurar tratamento. Os serviços de psiquiatria prescrevem medicações que visam a supressão dos sintomas, mas muitos pacientes relatam que as manifestações se intensificam - fato que gera ainda mais sofrimento. Essa questão nos levaria a pensar em uma série de problemas. No entanto, caberá aqui explorarmos o principal: o caráter de patologia atribuído às alucinações.

Nesse sentido, este artigo tem como objetivo problematizar o enfoque biomédico moderno sobre a alucinação auditiva. Para isso, buscou-se apresentar algumas noções de pensadores e filósofos de diferentes períodos históricos, bem como outras possibilidades de pensar o fenômeno, a partir da analítica existencial heideggeriana. Iniciaremos esse percurso com os gregos antigos.

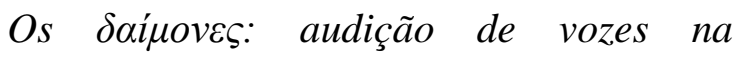
Antiguidade

${ }^{2}$ Descritos nos manuais utilizados pela medicina/psiquiatria: Classificação Internacional de Doenças (CID-10) e Manual Diagnóstico e Estatístico de Transtornos Mentais (DSM-V).

Mas desde que a terra encobriu essa raça, eles são divindades pela vontade de Zeus grande, nobres, terrestres, guardiões dos humanos perecíveis; \{eles vigiam as sentenças e as cruéis ações, vestidos de bruma, vagando por toda a terra,\} distribuidores de riquezas: obtiveram esse privilégio de reis. (2012, p. 75)

Nessa passagem, vemos que os $\delta \alpha i ́ \mu o v \varepsilon ́ \varsigma$ eram guardiões da justiça, já que vigiavam decisões de juízes, julgavam atos humanos, e em alguns casos distribuíam riquezas. Além disso, para Hesíodo os

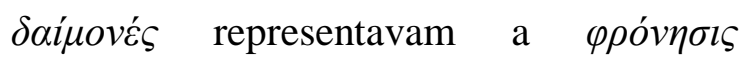
(phrônesis) do homem - qualidades da alma como o juízo sábio, a sagacidade e a prudência; uma espécie de sabedoria prática, própria do exercício meditativo. Por meio deles, o homem formulava juízos que o auxiliavam a tomar decisões. $\mathrm{E}$ quando a decisão resultava em um mal, os

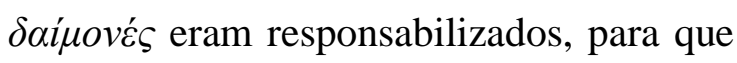
os homens se livrassem da culpa (SPINELLI, 2006). 
Segundo o Perseus $^{3}$, a palavra $\delta \alpha i ́ \mu \omega v$ (daímon) vem do radical $\delta \alpha i ́ \omega$ (daío), e tem diversos significados: dividir ou distribuir destinos; deus ou deusa; divindade ou poder divino ${ }^{4}$; o gênio da pessoa, sua sorte ou sua fortuna; um espírito maligno ou demônio. E o

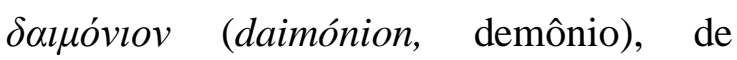
acordo com o politeísmo antigo, designava gênio mal ou bom (RAMIZ GALVÃO, 1994). Em Hesíodo, o Perseus fornece ainda uma consideração específica sobre os

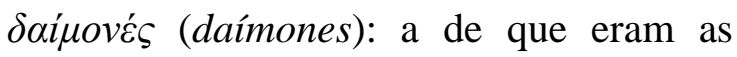
almas dos homens que viviam na Era de Ouro, e faziam a ligação entre os homens e os deuses.

Pensadores ligados à tragédia, como Eurípedes, também tematizaram o

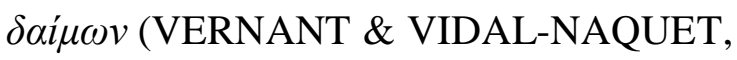
2011). Mas ele foi pensado principalmente por Heráclito, Parmênides e Demócrito, para os quais o $\delta \alpha i \mu \omega v$ representava um poder que poderia impelir tanto para o mal, como para o bem. Um efeito negativo dizia respeito à falta de capacidade do homem em gerir de maneira racional suas

${ }^{3}$ Ferramenta digital que, além de dicionário, é biblioteca, e se dedica à cultura greco-romana. É a versão eletrônica do dicionário Lidell-Scott-Jones. Maiores informações em: http://www.perseus.tufts.edu/hopper/

${ }^{4}$ Difere-se de $\theta \varepsilon o ́ \varsigma$ (theós), em razão desta palavra denotar uma divindade individual, enquanto que o $\delta \alpha i \mu \omega v$ era considerado uma divindade de ordem mais baixa (EDWARD, 1872). emoções, vontades, paixões e desejos ${ }^{5}$ (SPINELLI, 2006). Ou seja, ele designava a loucura, que no cenário grego era tomada

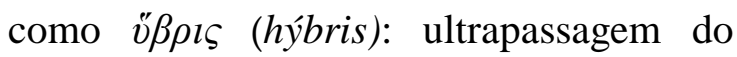
métron, perda da medida, "desatenção do homem às limitações e às fragilidades próprias ao ser humano" (FEIJOO, 2016, p. 7) - incapacidade de governar a si mesmo. Assim, o $\delta \alpha i \mu \omega v$ representava um intruso, que interferia e coagia, não na qualidade de um ser, mas de "um acontecer (por um vigor) inerente à alma (sede da vontade e do arbítrio deliberativo do humano), à qual se interpõe - sobrepondose, inclusive, aos ditames da razão" (SPINELLI, 2006, p. 49).

Sócrates foi um dos primeiros homens a relatar que ouvia vozes (o $\delta \alpha i \mu \omega v)$. Afirmou que elas eram diferentes de seus pensamentos, e que o auxiliavam a tomar decisões (PLATÃO, 2002). Uma das razões que o levou à morte se deu em função desse $\delta \alpha i ́ \mu \omega v$, já que, ao tomá-lo como guia, ele não precisava se submeter a questões religiosas do Estado, e nem de ser governado por ele (KIERKEGAARD, 1991). Um de seus discípulos, Platão,

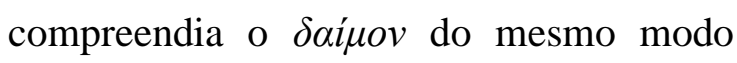

\footnotetext{
${ }^{5}$ Heráclito promoveu uma quebra na ideia da soberania do cosmos no pensamento grego, já que a phýsis deixou de reger a destinação do homem, passando este a ser o responsável por conduzir seu dever ser. Assim como ele, Parmênides e Demócrito acreditavam que os resultados das ações humanas deveriam ser imputadas unicamente aos

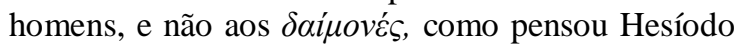
(SPINELLI, 2006).
} 
que Hesíodo - como um mensageiro que fazia a "ponte comunicacional" entre deuses e homens. Na obra "O banquete" (Platão, 2016), Diotima, ao ser interpelada por Sócrates sobre o que achava do amor, respondeu: "Um grande gênio ${ }^{6}$, ó Sócrates; e com efeito, tudo o que é gênio está entre um deus e um mortal" (202 d-e). E sobre sua $\delta v v \alpha \mu \iota$ (dynamis), ela afirmou:

$\mathrm{O}$ de interpretar e transmitir aos deuses o que vem dos homens, e aos homens o que vem dos deuses, de uns as súplicas e os sacrifícios, e dos outros as ordens e as recompensas pelos sacrifícios (...) Por seu intermédio é que procede não só toda arte divinatória, como também a dos sacerdotes que se ocupam dos sacrifícios, das iniciações e dos encantamentos, e enfim de toda adivinhação e magia. (202 e, 203 a)

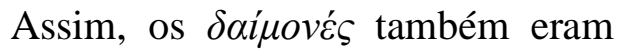
seres que inspiravam ou influenciavam homens a desempenharem as artes divinatórias - os oráculos, sacerdotes e/ou homens envolvidos na arte da adivinhação, premonições ou pressentimentos. Já no “Fédon", Platão (2011) pensou em uma

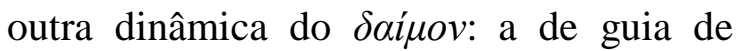
almas. As almas que compreendiam o estado do pós-vida, e que haviam conduzido suas vidas da melhor forma possível, seguiam seus guias de forma obediente; as que não haviam seguido esse caminho, e apresentavam resistência, eram

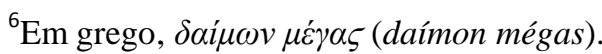

conduzidas de forma coercitiva pelo

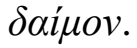

De modo diferente de seus predecessores, Aristóteles utilizou o conceito de $\delta \alpha i ́ \mu o v$ dentro de uma outra

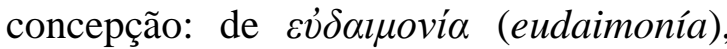
ou felicidade. Mas há um outro ponto a ser destacado em seu pensamento. Segundo Zanello e Martins (2010), o estagirita foi o responsável por firmar uma questão que havia tido início com Platão: a separação entre $\mu \tilde{v} \theta o \varsigma$ (mythos) e $\lambda o ́ \gamma o \varsigma$ (lógos). Desse modo, se antes a palavra era entendida como verdade - dizia-se a coisa ela mesma -, em Aristóteles há a necessidade de se provar no discurso o que não é verdadeiro, dada a preocupação que ele tinha com o uso inadequado da palavra pelos sofistas. Com isso, "A metáfora perde a partir daqui sua inscrição em um programa filosófico e passa a ser considerada como mera figura estilística de linguagem, um adorno fútil e extremamente perigoso para um discurso que busque a verdade" (ZANELLO \& MARTINS, 2010, p. 191). Esse acontecimento influenciou sobremaneira o pensamento da humanidade, e atingiu seu ápice na Modernidade, como veremos mais à frente.

Apesar de ter discorrido pouco

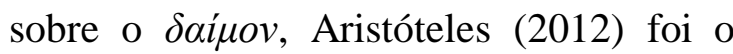
primeiro a escrever sobre o "mecanismo" da alucinação (FEINBERG, 1970), ao 
afirmar que "a faculdade que produz nossa ilusão quando doentes durante a vigília é a mesma que produz esse estado passivo durante o sono" (428 b-25). Sobre a realidade dos fenômenos, Aristóteles sublinhou que ela era dependente do horizonte no qual nos encontramos, e que nossos sentidos podem se enganar: "mesmo quando os indivíduos gozam de ótima saúde e conhecem as reais medidas do sol, este lhes parece medir somente um pé" (428 b-25). Assim, qualquer pessoa pode alucinar, estando ou não acometida por alguma doença; a audição de vozes é uma possibilidade do humano, e faz parte da faculdade de senso-percepção.

Depois de Aristóteles, cabe mencionar a figura de Cícero, já que foi ele quem utilizou pela primeira vez na história o termo "alucinação", segundo Lewis e Short (1891). Na obra "De Natura Deorum", a palavra utilizada para designar uma alucinação foi halucinatus, quando Cota criticava os ensinos de Epicuro: "O fato é que vocês, pessoas, se limitam a repetir mecanicamente essas afirmações que Epicuro pronunciou em suas visões alucinatórias em sonho" (CÍCERO, 1967, p. 69). Assim como Aristóteles, Cícero deixou em um mesmo plano as alucinações e os efeitos ilusórios dos sonhos.

Um último personagem a ser destacado na Antiguidade é Agostinho, que teve experiências de audição de vozes. $\mathrm{Na}$ obra "Confissões", ele relatou: "Mas eis que, de repente, ouço da casa vizinha uma voz, de menino ou menina, não sei, que cantava e repetia muitas vezes: "Toma e lê, toma e lê" (2007, p. 78). Nessa época, Agostinho passava por um momento de crise: não sabia se continuava a investir na vida espiritual, ou se seria melhor mudar os rumos, seguindo os "ditames" da vida carnal, e tal indecisão lhe trazia muita angústia. Após escutar a voz dessa criança, ele a entendeu como uma mensagem divina; decidiu então abrir a Bíblia, e atender à primeira passagem que lesse.

E encontrou a seguinte mensagem: "Não caminheis em glutonarias e embriaguez, não nos prazeres impuros do leito e em leviandades, não em contendas e rixas; mas revesti-vos de nosso Senhor Jesus Cristo, e não cuideis de satisfazer os desejos da carne” (2007, p. 79). Com isso, o místico afirmou: "Não quis ler mais, nem era necessário. Quando cheguei ao fim da frase, uma espécie de luz de certeza se insinuou em meu coração, dissipando todas as trevas de dúvida" (p. 79). Ou seja, a experiência alucinatória o auxiliou a tomar uma decisão, e, assim, a sair da crise.

Considerando o que foi apresentado, vemos que a audição de vozes e outras experiências "místicas" ou sobrenaturais, na Antiguidade, não eram consideradas sintoma de adoecimento mental - pelo contrário, já que serviam 
para abrir caminhos (entre outros sentidos). Porém, a partir do século $\mathrm{V}$ - período em que se iniciou a Era Medieval (LE GOFF, 2013) -, as bases de uma ciência psicopatológica começavam a ser fundadas.

Vozes entre os medievais: possessão demoníaca ou sinal de santidade?

As noções medievais de psicopatologia foram marcadas por uma forte relação entre loucura e possessão demoníaca. Com a consolidação do cristianismo, duas correntes se apresentavam: uma que pregava que qualquer divindade pagã (entre elas o $\delta \alpha \alpha i ́ \mu o v)$ deveria ser entendida como de ordem demoníaca, e que adorá-la seria o mesmo que cultuar o demônio; e uma outra que nomeava como hereges (ou pagãs) as pessoas que não seguiam a doutrina cristã - e portanto seriam partidárias ou obreiras do demônio (PESSOTI, 1994).

Quanto à audição de vozes e fenômenos de ordens similares, cabe destacar o personagem que mais contribuiu para mudanças na forma de compreendêlos: Tomás de Aquino. No século XIII, ele escreveu uma obra muito importante para a filosofia medieval, a "Suma Teológica", a qual foi baseada em noções aristotélicas, e contém boa parte de seu saber filosófico, teológico, psicológico e sociológico (KRAPF, 2001). Para podermos entender sobre suas ideias no campo da psicopatologia, e como o teólogo pensou acerca de fenômenos como a audição de vozes, é necessário discorrermos primeiro sobre sua biologia e psicologia.

Echavarría (2008) afirmou que Tomás se utilizou da teoria dos humores para explicar o processo de adoecimento do corpo e da alma. Quando os humores se esfriavam ou esquentavam demais, ou ficavam secos ou úmidos demais, funcionando de forma indevida (desequilíbrio orgânico), o sujeito era acometido por uma enfermidade. E os transtornos mentais seriam consequências de alterações do organismo; ou seja, as paixões do corpo afetariam a alma: "a dor sensível do corpo impede-nos a alma de sentir o prazer da virtude" (SANTO TOMÁS DE AQUINO, 1936, p. 2.490). Portanto, a enfermidade poderia produzir mal-estar, dor e cansaço, e assim causar uma dor psíquica, como a tristeza emoção que representava a paixão com mais propriedade, e que era muito danosa ao corpo, já que tirava a pessoa de sua disposição natural e a privava do uso da razão, segundo Tomás (1936).

Além disso, o teólogo afirmou que "sendo-nos a dor corporal mais sensível, e a apreensão sensitiva mais manifesta, 
resulta que a intensidade da dor corpórea faz quase desvanecer-se o prazer espiritual, relativo ao fim da virtude" (1936, p. 2.490). Há aí, portanto, uma ideia de psicossomática, que provém da noção aristotélica da unidade psicofísica do homem (KRAPF, 2001). A psique (alma) fazia parte do mesmo mecanismo, por estar inteira no corpo, e constituir o seu ato: "Os membros corpóreos obedecem às concepções da alma, quanto ao movimento local, por terem em si mesmos um princípio vital" (SANTO TOMÁS DE AQUINO, 1936, p. 867).

Quanto ao tema da loucura, Tomás (1936) a referenciou como falta de razão: "Pois, quem vai ser batizado deve ter a intenção de receber o batismo, como se disse. Ora, os loucos e os dementes, não tendo o uso da razão, não podem ter senão uma intenção desordenada" (p. 3.425). O santo afirmou ainda que "a enfermidade da alma é mais grave que a do corpo" (p. 1.429). A insanidade mental, como deficiência do uso da razão, poderia ser provocada de duas formas: por um mal funcionamento do corpo, a ponto da razão não poder intervir, e por uma elevada intensidade (um excesso) das paixões. A tristeza profunda também poderia ser causa da loucura, bem como a ira e o amor.

Sobre as manifestações do mundo espiritual, Tomás (1936) afirmou que começavam por meio de "visões sensíveis" (p. 3.188). E quanto à audição de vozes, as manifestações poderiam ser provenientes:

- de Deus: "Ora, pelo batismo que recebeu Cristo se manifestou suficientemente; quer também pelo testemunho de João; quer pela descida da pomba; quer também pelo testemunho da voz paterna" (p. 3.178);

- de anjos: “Os anjos, propriamente, não falam pelos corpos assumidos, mas por um símile de locução, enquanto formam, no ar, sons semelhantes às vozes humanas" (p. 487);

- do diabo: "Pois, Cristo venceu eficacissimamente o seu tentador. Mas este depois atacou-o de novo, incitando os Judeus a que o matassem. Logo, não é verdade que o diabo vencido cessa de atacar" (p. 891);

- de demônios: "Quando expressamente invocados, os demônios costumam predizer o futuro de muitos modos. - Ora, por meio de aparições prestigiosas, manifestando-se aos olhos e aos ouvidos dos homens, para prenunciar o futuro" (p. 2336).

Tomás de Aquino (1936) não considerou a audição de vozes como sinal de loucura, mas sim as paixões intensas (“desenfreadas"). Nesse ponto, o teólogo se alinhou ao pensamento dos antigos quando afirmaram que as paixões levavam à $v \beta \beta \rho \iota$. E há ainda uma consideração a ser destacada: Aquino abriu possibilidade para 
que os escolásticos analisassem as experiências sobrenaturais conforme sua fonte e conteúdo, ou seja, se as manifestações se referiam ao reino dos céus ou ao inferno (SARBIN \& JUHASZ, 1967). Em se tratando do inferno e de experiências avaliadas como demoníacas, a pessoa era primeiramente considerada herege - por ser contra a doutrina da Igreja Católica -, e acusada de bruxaria pela Inquisição; em seguida, era humilhada e sofria escárnio publicamente, para, por fim, ser queimada viva nas estacas (SARBIN \& JUHASZ, 1967).

Dessa forma, Tomás influenciou a Igreja Católica a compreender esses fenômenos como sinal de bruxaria ou feitiçaria (PESSOTI, 1994), possessão demoníaca ou ainda santidade (BAKER, 2009) - já que, sendo a fonte e o conteúdo da ordem dos reinos celestiais, se estaria mais próximo do bem supremo (Deus). Com isso, havia duas possibilidades (como destinação) para ouvidores de vozes: a salvação, ou a condenação.

As questões do Tractatus de Angelis (50-64), da Suma Teológica de Tomás, inspiraram inquisidores como Sprenger, Institor, e Fra Eliseo Masini, e também exorcistas famosos à época, como Menghius, a escreverem seus tratados. Três dessas questões sobre os demônios, em especial, foram fatais: a de que eles possuíam o saber sobre o funcionamento das coisas naturais; a de que todo e qualquer demônio, por ter feito mau uso de sua vontade livre, mesmo com a permissão divina, optou por ser perverso; e a de que eles habitavam o éter, de onde desceriam para despertar o mal nos seres humanos (PESSOTI, 1994).

Essas três questões foram utilizadas na estruturação da obra "Malleus Maleficarum" (“O Martelo das Bruxas”) a que mais contribuiu para sistematizar e operacionalizar procedimentos do tribunal da Inquisição (SARBIN \& JUHASZ, 1967) -, e ficam evidentes no recorte a seguir:

Certos homens os quais são chamados Lunáticos são molestados por demônios mais durante um certo tempo do que outro; e os demônios não apenas se comportariam dessa forma, mas prefeririam molestá-los todo o tempo, a menos que eles mesmos fossem afetados profundamente por certas fases da Lua. (...) E isso também é aduzido como uma prova; de acordo com Santo Agostinho (Cidade de Deus, v. 10), os demônios empregam certos corpos inferiores, como ervas, pedras, animais, e certos sons e vozes, e figuras. (KRAMER \& SPRENGER, 1971, p. 31, tradução minha)

Assim, os considerados loucos, àquela época, recebiam influência direta dos demônios, e padeciam em função deles, por meio de manifestações diversas, dentre elas as vozes. Muitos hereges foram considerados loucos endemoniados 
(ESQUINSANI \& DAMETTO, 2012), e, por terem dissidido da Igreja Católica, foram perseguidos pela Inquisição de forma severa e condenados (O’BRIEN, 1950). Portanto, diferentemente do que aconteceu na Antiguidade, os medievais analisavam casos de audição de vozes de acordo com pressupostos religiosos, e foram radicais (condenando e levando pessoas à morte) em função do crescente mal que assolava o mundo, entre outros fatores (HUIZINGA, 1922).

Tomás de Aquino, personagem central desse cenário, influenciou também o pensamento dos tempos iniciais da Modernidade (WOLKMER, 2001). Seus pressupostos foram utilizados para dar sustentação à práxis de muitos alienistas e ao advento da psiquiatria, a qual, como veremos a partir do próximo tópico, se tornou a ciência por excelência no tocante à análise e tratamento do que viria a ser chamado de "alucinação auditiva".

O fim da Filosofia como caráter fundador da alucinação como sintoma de doença

Com o ego cogito de Descartes, diz Hegel, a Filosofia pisou pela primeira vez terra firme, onde pode estar em casa. Se com o ego cogito, como subjectum por excelência, é atingido o fundamentum absolutum, isto quer dizer: o sujeito é o hypokeímenon transferido para a consciência, é o que verdadeiramente se presenta, o que na linguagem tradicional se chama, de maneira mui pouco clara, de substância. (HEIDEGGER, 1999a, p. 100)

Com essa passagem, Heidegger sublinhou que, na Modernidade, a consciência foi tomada como ponto nevrálgico do ser do homem. Tal período histórico teve início com uma crise no pensamento medieval europeu, a qual se deu em virtude de três grandes acontecimentos históricos: a Reforma Protestante, o Movimento Iluminista, e a Revolução Francesa (FREITAG, 1995). Para os filósofos modernos importava averiguar quais dimensões da consciência (imaginação, vontade, memória, intelecto) poderiam ser conhecidas realmente, e de que forma a vontade poderia ser dominada para que se chegasse ao conhecimento da verdade (CHAUÍ, 2000).

Segundo Descartes (2001): “quer estejamos acordados, quer dormindo, nunca nos devemos deixar persuadir senão pela evidência de nossa razão, e não de nossa imaginação, nem de nossos sentidos" (p. 45). Assim, o conhecimento obtido por meio do sensível seria uma fonte de erro. Já Locke (1999) afirmou que seria por meio da percepção que chegaríamos ao conhecimento; porém, haveria necessidade de que a razão tornasse esse conhecimento verdadeiro, através de provas. As 
alucinações, dentro dessa lógica, seriam consideradas algo da ordem da fantasia, e, portanto, um erro dos sentidos/percepção ${ }^{7}$.

Assim, as duas correntes dominantes (o racionalismo e o empirismo), no campo da percepção, contribuíram para uma redução dos fenômenos que não se interpunham no campo do visível (CHAUÍ, 2000) - como as alucinações. No século XVIII, com Kant, o fundamento passou a possuir o "caráter do fundar" como "possibilitação transcendental da objetividade dos objetos" (HEIDEGGER, 1999a, p. 96). Portanto, o que apareceu como fundamento foi a subjetividade; o ser foi tomado como objeto, e, para conhecê-lo, haveria necessidade de pensá-lo a partir de categorias como espaço e tempo (HEIDEGGER, 2001). Kant foi o primeiro a pensar o ser do homem por meio do projeto científico-natural de Galilei e Newton. A partir daí, passou-se a ter "a pretensão de determinar o ser-homem por

\footnotetext{
${ }^{7}$ Já que não eram verdades autoevidentes. Cabe aqui retomarmos o acontecimento referente à perda da linguagem metafórica, em Platão e Aristóteles (citado no tópico referente à Antiguidade). Se em Aristóteles ela ocorreu em razão da busca pela verdade, na Modernidade essa busca atingiu o seu extremo. Com isso, a compreensão das alucinações perdeu potência, considerando que apenas recentemente (há cerca de 30 anos) alguns pesquisadores, profissionais da saúde mental e pensadores, ao analisarem casos de audição de vozes, chegaram ao entendimento de que elas podem ter também uma função metafórica (BAKER, 2009; ROMME, 2009; CORSTENS \& LONGDEN, 2013). Ou seja, demoramos aproximadamente 2.500 anos para voltarmos a entender as alucinações como linguagem.
}

meio de um método que absolutamente não foi projetado em relação à sua essência peculiar" (HEIDEGGER, 2001, p. 53).

Além dessas noções, Kant acrescentou à razão "a possibilidade de se transformar no campo transcendental de determinação da ação" (CASANOVA, 2013, p. 33). Desse modo, o homem seria capaz de reger sua destinação - controlar suas decisões e comportamentos - pela razão. Mas aí residiria um problema, já que somente um ser poderia ter uma vontade submetida à razão, ou fazer com que elas não se diferenciassem: Deus. Então, para que o homem se aproximasse da ideia de "perfeição" divina, adequando a vontade à razão (o que lhe conferiria autonomia moral), ele deveria se exercitar plenamente no uso da razão, ao vencer o aprisionamento "em sua constituição sensível" (CASANOVA, 2013, p. 35).

A consideração kantiana acerca de Deus enquanto postulado da razão prática, que inspiraria o homem a construir o bem supremo, abriu um horizonte que foi explorado e apropriado por Hegel (CASANOVA, 2013). No recorte apresentado no início deste tópico, vimos que Hegel creditou ao ego cogito a inauguração da filosofia, o seu fundamento. Esse fundamento significou para ele a noção de autoconsciência, ou o "pensamento pensado" (HEIDEGGER, 1999a, p. 100), que aconteceria no 
movimento dialético - o método correto para o pensamento filosófico. A dialética especulativa, segundo Hegel (2005), era "uma exibição do conceito que é em si, e ao mesmo tempo é o ir-para-dentro-de-si próprio de ser, um aprofundamento de estar em si mesmo" (p. 186, tradução minha). Assim, com Hegel, “o pensamento moderno é instado a passar do terreno do entendimento (Verstand) e da finitude para o terreno da razão (Vernunft) e da infinitude" (FERNANDES, 2017, p. 36).

Portanto, a partir do cogito ergo sum, e com Kant, e depois Hegel, o homem moderno passou a ter o governo de si, ou seja, a ser autônomo em sua destinação, a ter o controle de sua vida, de suas decisões e comportamentos; em suma, ele passou a ser entendido como fundamento de todas as verdades possíveis (HENRY, 2009). A consciência tomou o lugar que o $\pi \alpha \dot{\theta} \theta o \varsigma$ e a instância divina ocuparam na existência humana até esse período histórico. E trouxe outro problema, que foi apresentado por Heidegger (2002):

A bétula nunca ultrapassa o seu possível. As abelhas moram no seu possível. Só a vontade que, a toda parte, se instala na técnica, esgota a terra até a exaustão, o abuso e a mutação do artificial. A técnica obriga a terra a romper o círculo maduro de sua possibilidade para chegar ao que já não é nem possível e, portanto, nem mesmo impossível. (p. 85)
Essa passagem diz respeito ao fim da filosofia (ou consumação da metafísica), já que o homem moderno, autoconsciente e fundador de mundo, com sua "vontade de vontade" (HEIDEGGER, 1999b, p. 67), passou a ultrapassar seus limites, para alcançar o impossível. Essa vontade de vontade caracteriza a "era da técnica" (HEIDEGGER, 2007, p. 386), e representa o acabamento da metafísica também em função de promover uma autonomia das ciências em relação ao pensamento meditativo, ao pensamento que pensa o sentido do ser (HEIDEGGER, 1999a). Com essa busca pela dominação da vontade, "de substituição do possível ou do que realmente é, do só possível, a saber, a vida, a existência", "Há, faz-se uma doença. O homem está doente do homem..." (FOGEL, 2010, p. 10).

Essa sanha da vontade de querer do homem moderno é a própria $v ̋ \rho \imath \varsigma$ (hýbris) (FOGEL, 2010). Assim, o homem do cogito ergo sum, autoconsciente, controlador de seus comportamentos, regente de sua existência, e visando o infinito de suas possibilidades, quanto mais deposita sua fé na técnica, mais se perde de si, e se lança justamente no sentido contrário ao que crê ser. A consumação da filosofia serve de pilar para o modo como a ciência biomédica se estruturou e pensou as alucinações, como veremos a seguir. 
Horizonte biomédico moderno e alucinação auditiva

Ao analisar o horizonte biomédico moderno, Heidegger (2001) sublinhou que nele vigora uma tentativa (através do método científico-natural) de alcançar a cura $^{8}$ do corpo, e que muitos métodos eficientes são provenientes de resultados de estudos pautados nessa lógica; "mas a maioria admite que não é possível atingir de modo científico natural o que é central no homem.” (p. 54). E essa busca da cura é orientada pela descoberta de signos patognomônicos, os quais permitem indicar com precisão um mal a ser tratado. Cabe ressaltar que "o sintoma é estritamente ligado ao ser do paciente, mesmo que este entenda que não faz parte dele e deseje urgentemente se ver livre do mesmo" (MARTINS, 2003, p. 30).

No entanto, essa lógica atende de forma adequada os anseios de ramos da medicina que se destinam ao trato de patologias acerca das quais é possível estabelecer uma relação de causa e efeito ${ }^{9}$. No campo da saúde mental, em que o ser

\footnotetext{
${ }^{8}$ No sentido moderno da palavra, que significa remissão de sintomas, ou ausência de doença. Cabe ressaltar que a palavra cura é latina, e foi traduzida da língua grega - a qual a designava através do termo $\theta \varepsilon \rho \alpha \pi \varepsilon v ́ \omega$ (therapeuo), que significava "cuidar", segundo o dicionário Perseus.

${ }^{9}$ Como por exemplo, quando alguém sente dor ao descomprimir o abdome, sintoma típico de irritação peritoneal (MARTINS, 2003).
}

do homem não possui uma localização específica no $\operatorname{corpo}^{10}$, não há como se estabelecer um signo patognomônico (MARTINS, 2003), ou seja, uma relação de analogia entre um sintoma e o diagnóstico de uma doença, em quase todos os quadros clínicos - como acontece atualmente entre as alucinações auditivas e a esquizofrenia, por exemplo. Mas esse tem sido um dos objetivos da ciência psiquiátrica que, desde seus primórdios, se dedicou obstinadamente a procurar as causas das doenças mentais.

Essa sanha da psiquiatria se consolidou no século XIX, quando houve a legitimação do asilo como instituição de tratamento para a insanidade (FOUCAULT, 1991; 2010). Nessa mesma época, a "loucura" passou a ser entendida mais como uma "desordem na maneira de agir, de querer, de sentir paixões, de tomar decisões e de ser livre" (FOUCAULT, 2010, p. 121). Ou seja, a loucura era entendida como algo da ordem da desrazão e do descontrole. Como vimos anteriormente, essas noções foram formuladas por Tomás de Aquino, e eram refutadas pelo espírito moderno, em Descartes e Kant - que desconsideraram a

\footnotetext{
${ }^{10}$ Essa ideia é constestada pelas neurociências, que insistem em afirmar o ser por meio de experimentos cerebrais, em uma lógica "cérebro-centrista", como se esse órgão fosse o próprio humano (AZIZE, 2010) e a explicação para todos os seus mistérios.
} 
dimensão do sensível como doadora de verdade.

Tal forma de compreensão contribuiu para estigmatizar os "loucos" e excluí-los da sociedade (com a internação no manicômio), fato que ainda não havia se configurado nos séculos anteriores, já que, até então, a loucura pertencia às quimeras do mundo, e a privação de liberdade acontecia apenas quando se cometiam atos perigosos. O manicômio produzia a doença mental do interno a partir de relações de poder que funcionavam e eram mantidas por uma estrutura disciplinar, constituída por uma equipe técnica de médicos, enfermeiros, vigilantes e serventes - que sabiam o que era melhor para o doente. Foucault (2010) comparou a psiquiatria à botânica, ao afirmar o manicômio como local de classificação e diagnóstico, onde as espécies das doenças eram divididas de forma compartimentada. Além disso, tal instituição tinha o médico como mestre da loucura - o "produtor da verdade" (p. 122).

Era esse o cenário estruturado pela ciência biomédica no século XIX, tendo de um lado técnicas necessárias para se chegar a uma verdade - mas que eram baseadas em um tratamento moral/disciplinador, questão esta que também corresponde ao espírito moderno , e de outro pessoas em sofrimento que não tinham possibilidade de viver conforme suas próprias determinações. Entre as técnicas utilizadas, o trabalho figurava como uma importante medida, pois não havia espaço para a não produção; o interno tinha que ser útil ou ter uma função. Essas características se referem à consumação da metafísica, dentro da noção heideggeriana da técnica.

Além da vontade de vontade, da crença no controle e da busca pelo infinito, a técnica é o tempo em que o modo de ser do homem e o relacionamento com o seu mundo se pauta por um critério de utilidade e funcionalidade, de modo que aquilo que foge a esse critério acaba sendo descartado. E o descarte é o caminho dado às pessoas que relatam grave sofrimento em decorrência de alucinações, já que, como vimos, elas são enquadradas pelo nosso horizonte dentro de quadros psicopatológicos, e por isso são encaminhadas para se tratarem em instituições - que aprisionam o ser, por se destinarem a adequar as pessoas a padrões de normalidade (em vez de cuidarem das questões mesmas), e por serem em grande parte manicomiais.

É importante salientar que esse modo de compreensão das alucinações no horizonte moderno começou a se estruturar com Teresa de Ávila, personagem que empreendeu esforços na luta contra a existência da Santa Inquisição, a fim de proteger suas freiras que alucinavam 
(SARBIN \& JUHASZ, 1967). Teresa (1577/1921), que também era ouvidora de vozes, afirmou em sua obra que as manifestações sobrenaturais não eram algo de ordem religiosa ou espiritual, mas que representavam estados doentios. Assim, baseada em pressupostos tomasianos, a santa trocou o julgamento da Igreja pelo crivo da ciência, e abriu possibilidade para que, desde os primeiros tempos da Modernidade, muitos teóricos se dedicassem ao estudo das alucinações.

Nos séculos XVI e XVII foram escritos alguns textos sobre experiências sobrenaturais ainda sob a influência do cristianismo. Porém, no século XVIII, diversos alienistas se dedicaram à temática com aportes da nova ciência emergente, em especial a neurofisiologia (BERRIOS, 1996). Alguns deles, a partir da experiência clínica com pacientes que alucinavam, acabaram por entender $\mathrm{o}$ fenômeno como algo da ordem da insanidade. E no século seguinte, quatro personagens tiveram um papel fundamental para que a audição de vozes fosse considerada sintoma de doença mental: Esquirol, Kraepelin, Bleuler e Schneider.

Esquirol foi quem popularizou a palavra alucinação no meio científico, em 1838 (PAIM, 1993). Até meados do século XIX, pesquisadores e profissionais da França (país de referência da psiquiatria à época) tiveram diferentes posicionamentos acerca das alucinações, entre elas uma corrente que insistia em afirmar que elas eram decorrentes de insanidade, e outra que procurava analisar o contexto de vida e o caráter da experiência (SMITH, 2008). Da segunda metade desse século em diante, a escola alemã se tornou a principal referência, em função de trabalhos de teóricos como Kraepelin (LOUZÃ NETO \& ELKIS, 2007).

Kraepelin, em 1893, fixou o fenômeno da audição de vozes como sintoma de doença mental, ao apresentar o conceito de demência precoce, e associar a ele os delírios e alucinações. Bleuler seguiu essa mesma lógica, porém substituiu o termo demência precoce por esquizofrenia (LOUZÃ NETO \& ELKIS, 2007). E após Bleuler, Schneider contribuiu para reduzir ainda mais as possibilidades de compreensão das alucinações, quando lançou a noção de sintomas de primeira ordem da esquizofrenia - a qual serviu para a Organização Mundial da Saúde considerar a esquizofrenia como uma doença universal (ELKIS, 2000).

Dessa forma, esses e outros tantos personagens (desde Platão e Aristóteles) contribuíram para a estruturação de uma tradição científica que, tendo sua $\pi \rho \tilde{\alpha} \xi \iota \varsigma$ (práxis) ancorada no zeitgeist moderno, obscureceu o fenômeno da audição de 
vozes (por reduzir suas possibilidades de compreensão, e fixá-lo em apenas uma posição), e transformou-o em um signo que deve ser suprimido a qualquer preço, dado o seu caráter de anormalidade e a sua associação com a loucura. Ao se tentar adequar os ouvidores de vozes ao mundo da técnica, através de medicações e prescrições de dever-ser, realiza-se o mesmo papel de ortopedia moral ${ }^{11}$ que caracterizou a práxis psiquiátrica desde sua fundação. Portanto, a obnubilação do pensamento de pesquisadores e profissionais ligados ao campo da psicopatologia representa a própria consumação da metafísica - tempo que não suporta a finitude da existência, e que busca corrigí-la a todo custo.

No próximo tópico, serão apresentados alguns elementos da analítica existencial heideggeriana, os quais podem nos auxiliar a meditar sobre o fenômeno da audição de vozes de forma diferente da que propõe a lógica biomédica moderna.

Audição de vozes como possibilidade de ser do-ente

Para não incorrermos na mesma condição configurada pelo mundo da

\footnotetext{
${ }^{11}$ Conceito trabalhado por Foucault (2011).
}

técnica, e considerando que o pensamento metafísico se consumou - o que exige de nós um outro pensar -, de que modo poderíamos meditar sobre o fenômeno da audição de vozes?

Embora nosso tempo se arrogue o
progresso de afirmar novamente a
"metafísica", a questão aqui
evocada caiu no esquecimento
(...) A questão referida não é, na
verdade, uma questão qualquer.
Foi ela que deu fôlego às
pesquisas de Platão e Aristóteles
para depois emudecer como
questão temática de uma real
investigação. O que ambos
conquistaram manteve-se, em
muitas distorções
"recauchutagens", até a Lógica de
Hegel. (HEIDEGGER, 2012, p.
37)

Nessa passagem, Heidegger (2012) nos chama a atenção para o aspecto da "real investigação", que se daria através de um método para se chegar à "sache" (questão ou coisa) (HEIDEGGER, 1999a, p. 99); mas não a mesma proposta pela tradição (de Platão a Hegel), já que por meio dela vimos que houve uma redução na compreensão das alucinações enquanto fenômeno. Propomos aqui justamente meditar o próprio fenômeno, enquanto método. Ou seja, pensar a audição de vozes como fenômeno no sentido original formal desta palavra, que vem do grego paívw (phainô), e significa "aquilo que vem à luz - se mostra - a partir de si mesmo"12. Assim, o exercício fenomenológico de ir às

\footnotetext{
${ }^{12}$ Segundo o dicionário Perseus.
} 
coisas mesmas, não poderia abrir alguma possibilidade de compreensão sobre esse fenômeno?

Mas antes de pensarmos em respostas para essa pergunta, há nesse fragmento um ponto ainda mais importante a ser meditado, que é a questão fundamental da filosofia: "que é o ente? ( $t i ́$ tò ón)" (Heidegger, 1999c, p. 33). É ela que abre possibilidade para pensarmos o sentido do ser. No entanto, desde Platão ela se perdeu, como este artigo procurou mostrar através das noções presentes nos períodos históricos citados. Os gregos antigos compreendiam as vozes como possibilidades de ser, enquanto que, nos medievais, muitos ouvidores de vozes foram perseguidos e condenados - o mesmo acontecendo entre os modernos, com a diferença de que a condenação ganhou a roupagem da ciência biomédica. Portanto, ao nos convocar a pensar sobre a questão fundamental da filosofia, não estaria Heidegger (2012) abrindo possibilidade para pensarmos sobre $\mathrm{o}$ sentido das vozes?

Não seria tarefa do pensamento parar de pensar a alucinação como um ente metafísico, como falha ou erro da percepção, como algo da ordem do irreal ou da não verdade, para pensá-la como um poder ser? Uma questão mais simples ainda, que por si só já serviria para a destruição da lógica moderna, é a de que, se algumas pessoas desde a infância relatam ouvir vozes, e não necessariamente sofrem em função disso, e/ou conseguem realizar as atividades da vida hodierna, por que ainda se insiste em atribuir um sentido patológico ou de anormalidade a experiências alucinatórias?

Diante das questões levantadas, é mister trazermos à discussão a sentença heraclitiana " $\tilde{\eta} \theta o \varsigma \quad \dot{\alpha} v \theta \rho \omega ́ \pi \omega \quad \delta \alpha i \mu \omega v$ " (éthos anthrópos daímon). Segundo Heidegger (2005),

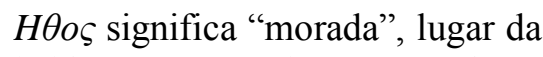
habitação. A palavra nomeia o âmbito aberto onde o homem habita. $\mathrm{O}$ aberto de sua morada torna manifesto aquilo que vem ao encontro da essência do homem e assim, aproximando-se, demora-se em sua proximidade. A morada do homem contém e conserva o advento daquilo a que o homem pertence em sua essência. Isto é, segundo a palavra de Heráclito, o $\delta$ ai $\mu \omega v$, o Deus. A sentença diz: o homem habita, na medida em que é homem, na proximidade de Deus. (p. 71)

Heidegger (2005) afirmou que Heráclito quis dizer: "A habitação (familiar) é para o homem a abertura para a presentificação do Deus (o in-sólito)" (p. 74). O filósofo alemão utilizou essa sentença principalmente para trabalhar a questão Ontológica (da verdade) do ser. O pensar edifica a casa do ser, mas seria somente a partir do pensar rigoroso (que busca o fundamento ou a essência do ser), e não do conceitual ou filosófico (do 
horizonte estabelecido pela tradição), que seria possível chegarmos ao entendimento do $\tilde{\eta} \theta o \varsigma$ e do $\delta \alpha i ́ \mu \omega v$.

Nesse sentido, deve-se pensar o homem não como um ser fechado em suas determinações, mas exatamente pelo contrário, como aberto e indeterminado. Somos possibilidade de vários modos de ser. E o $\tilde{\eta} \theta o \varsigma$, o habitar, a morada, quer dizer "o ente que sempre eu mesmo sou. A expressão "sou" conecta-se a junto; “eu sou", diz, por sua vez: eu moro, detenhome junto...ao mundo, como alguma coisa que, deste ou daquele modo, me é familiar" (HEIDEGGER, 2012, p. 100). Poderíamos, a partir daí, entender que as alucinações dizem respeito ao mundo do ouvidor de vozes, ao que lhe é familiar.

Assim, ao pensarmos sobre a audição de vozes, "não se deve partir da diferenciação entre 'real' e 'irreal', mas sim do exame do caráter da relação com o mundo em que o paciente se encontra no momento" (HEIDEGGER, 2001, p. 176). Tal ideia está presente no relato de Eliezer (apresentado no início deste texto), ouvidor de vozes que passou por várias internações em manicômios ao longo de sua existência, e que tinha muito receio de que isso acontecesse novamente - já que essas experiências lhe trouxeram grandes sofrimentos.

Atendendo a esse outro modo de pensar, deixaríamos nós de enxergar o ouvidor de vozes como doente, para compreendermos que sua experiência é uma possibilidade de ser do-ente?

\section{Referências Bibliográficas}

AGOSTINHO. Confissões. Digitação de Lúcia Maria Csernik, 2007. Disponível em: https://sumateologica.wordpress.com/. Acesso em: 15 de jun. de 2017.

AMERICAN PSYCHIATRIC ASSOCIATION. Manual Diagnóstico $e$ Estatístico de Transtornos Mentais: DSM5. Porto Alegre: Artmed, 2014. 992p.

ARISTÓTELES. Parva Naturalia. Tradução, textos adicionais e notas de Edson Bini. 1 ed. São Paulo: EDIPRO, 2012. 192p.

AZIZE, Rogério Lopes. O cérebro como órgão pessoal: uma antropologia de discursos neurocientíficos. Trab. Educ. Saúde, Rio de Janeiro, v. 8, n. 3, 2010. pp.563-574, nov.

BAKER, Paul. The voice inside: a practical guide for and about people who hear voices. Port of Ness: P\&P Press, 2009. 90p.

BERRIOS, German Elias. Disorders of perception. In G.E. Berrios. The history of mental symptoms: descriptive psychopathology since the 
nineteenth century. Cambridge: Cambridge University Press, 1996. p.35-70.

CASANOVA, Marco Antônio. Eternidade frágil: ensaio de temporalidade na arte. Rio de Janeiro: Via Vérita, 2013. 432p.

CHAUÍ, Marilena. Convite à filosofia. São Paulo: Ática, 2000. 440p.

CÍCERO. De natura deorum. In: Cicero in twenty-eight volumes, De natura Deorum, Academica. Translated by $\mathrm{H}$. Rackhan. London: Harvard University Press, 1967. Disponível em: https://ryanfb.github.io/loebolusdata/L268.pdf. Acesso em: 02 de fev. de 2016.

CORSTENS, Dirk; LONGDEN, Eleanor. The origins of voices: links between life history and voice hearing in a survey of 100 cases. Psychosis, v.5, n.3, 2013. pp.270-285.

DESCARTES, René. Discurso do método. Tradução de Maria Ermantina Galvão. São Paulo: Martins Fontes, 2001. 102p.

ECHAVARRÍA, Martín Federico. Las enfermedades mentales según Tomás de Aquino [I]. Sobre el concepto de enfermedad. Scripta Mediaevalia, Mendoza, n.1, 2008. pp. 91-115.

EDWARD, Henry. The daemon of Socrates. London: Longmans, Green, and Co., 1872. Disponível em: https://archive.org/. Acesso em: 09 de ago. de 2017.

ELKIS, Hélio. A evolução do conceito de esquizofrenia neste século. Rev Bras Psiquiatr, São Paulo, v. 22, s. I, 2000. pp. 23-26, mai.

ESQUINSANI, Rosimar Serena Siqueira; DAMETTO, Jarbas. Questões de gênero e a experiência da loucura na Antiguidade e na Idade Média. Estud. Sociol., Araraquara, v.17, n.32, 2012. pp. 205-222.

FEIJOO, Ana Maria Lopez Calvo. Apresentação. In: Feijoo, A.M.L.C. \& Lessa, M.B.M.F. Psicopatologia: fenomenologia, literatura e hermenêutica. Rio de Janeiro: IFEN, 2016. p.7-18.

FEINBERG, Irwin. Hallucinations, Dreaming and REM Sleep. In: Wolfram, K. Origin and Mechanisms of Hallucinations. New York: Springer, 1970. p.125-132.

FERNANDES, Marcos Aurélio. $D a$ contemporaneidade da filosofia. Texto de referência da disciplina de Filosofia Contemporânea, do curso de graduação em Filosofia, da Universidade de Brasília, 2017. Disponível em: http://www.profmarcosfernandes.com.br/. Acesso em: 10 de ago. de 2017.

FOGEL, Gilvan. O homem doente do homem e a transfiguração da dor: uma leitura de Da visão e do enigma em Assim 
falava Zaratustra, de Frederico Nietzsche. Rio de Janeiro: Mauad X, 2010. 172p.

FOUCAULT, Michel. História da loucura. São Paulo: Perspectiva, 1991. $608 p$. . Microfísica do poder. São Paulo: Edições Graal, 2010. 295p.

. Vigiar e punir: nascimento da prisão. Tradução de Raquel Ramalhete. 39 ed. Petrópolis: Vozes, 2011. 288p.FREITAG, Bárbara. Habermas e a teoria da Modernidade. Cad. CRH, Salvador, n. 22, 1995. pp. 138-163, jan/jun.

HEGEL, Georg Wilhelm Friedrich. Enciclopedia de las ciencias filosóficas em compendio. Madrid: Alianza Editorial, 2005. 630p.

HEIDEGGER, Martin. O fim da filosofia e a tarefa do pensamento. In: Conferências e escritos filosóficos. São Paulo: Nova Cultural, 1999a. p.95-108.

In:_ $\quad$ Posfácio $\quad$ (1943).
filosóficos. São Paulo: Nova Cultural, 1999b. p.65-73.

Que é isto - A filosofia?

In:

Conferências e escritos

filosóficos. São Paulo: Nova Cultural, 1999c. p.27-40.

Seminários de Zollikon.

Editado por Medard Boss. Tradução de Gabriela Arnhold e Maria de Fátima de
Almeida Prado. Petrópolis: Vozes, 2001. $312 \mathrm{p}$. . Ensaios e conferências. Tradução de Emmanuel Carneiro Leão, Gilvan Fogel, Márcia Sá Cavalcante Schuback. 8. ed. Petrópolis: Vozes, 2002. 269p. . Carta sobre o humanismo. Tradução de Rubens Eduardo Frias. São Paulo: Centauro, 2005. 89p.

A questão da técnica. [1953: Die Frage nach der Technik]. Tradução de Marco Aurélio Werne. Scientiae Zudia, São Paulo, v. 5, n. 3, 2007, pp. 375-398. - Ser e tempo. Tradução revisada e apresentação de Márcia Sá Cavalcante Schuback. 7 ed. Petrópolis: Vozes, 2012. 559p.

HENRY, Michel. Genealogia da psicanálise: o começo perdido. Tradução e notas de Rodrigo Vieira Marques. Curitiba: Editora UFPR, 2009. 368p.

HESÍODO. (2012). Os trabalhos $e$ os dias. Edição, tradução, introdução e notas de Alessandro Rolim de Moura. Curitiba: Segesta. 152p.

HOMERO. Ilíada. Tradução de Manoel Odorico Mendes. Revisado e digitalizado por Sálvio Nienkötter, 2009. Disponível em: https://iliadadeodorico.wordpress.com/. Acesso em: 05 de jul. de 2017. 
HUIZINGA, Johan. The waning of the middle ages. London \& Tonbridge: The Whitefriars Press Ltd, 1922. 352p.

KIERKEGAARD, Sören Aabye. $O$ conceito de ironia. Tradução de Álvaro Luiz Montenegro Valls. Petrópolis: Editora Vozes, 1991. 283p.

KRAMER, Heinrich; SPRENGER, James. The Malleus Maleficarum. Translated with introductions, bibliography and notes by Ver. Montague Summers. Ney York: Dover Publications Inc., 1971. 278p.

KRAPF, Eduardo. Tomás de Aquino y la psicopatología. Temas de historia de la Psiquiatría Argentina, Buenos Aires, v.11, 2001. pp. 1-4.

LE GOFF, Jacques. Para uma outra Idade Média: tempo, trabalho e cultura no Ocidente. Petrópolis: Vozes, 2013. 536p.

LEWIS, Charlton Thomas; SHORT, Charles. A New Latin Dictionary. New York: Harper \& Brothers Publishers, 1891. Disponível em: https://archive.org. Acesso em: 02 de fev. de 2016.

LOCKE, John. Ensaio acerca do entendimento humano. São Paulo: Nova Cultural, 1999. 319p.

LOUZÃ NETO, Mário Rodrigues; ELKIS, Hélio. 2. ed.Porto Alegre: Artmed, 2007. 588p.

\section{MARTINS, Francisco.}

Psicopathologia II: Semiologia Clínica:
Investigação Teórico Clínica das Síndromes Psicopatológicas Clássicas. Brasília: Universidade de Brasília, 2003. 396p.

O'BRIEN, John Anthony. The Truth About The Inquisition. Causes, Methods and Results. New York: The Paulist Press, 1950. 64p.

PAIM, Isaías. História da psicopatologia. São Paulo: Editora Pedagógica e Universitária, 1993. 167p.

PESSOTI, Isaías. A loucura e as épocas. São Paulo: Editora 34, 1994. 208p. PLATÃO. Apologia de Sócrates. Tradução de Maria Lacerda Moura. São Paulo: Ediouro, 2002. 138p. - Fédon. Texto grego de John Burnet. Tradução de Carlos Alberto Nunes. 3. ed. Belém: Editora UFPA, 2011. $215 p$.

O Banquete. Edição bilíngue. Tradução, posfácio e notas de José Cavalcante de Souza. 1 ed. São Paulo: Editora 34, 2016. 253p.

RAMIZ GALVÃO, Benjamin Franklin. Vocabulário etimológico, ortográfico e prosódico das palavras portuguesas derivadas da língua grega. Rio de Janeiro/Belo Horizonte, Livraria Garnier, 1994. 608p.

ROMME, Marius. Metaphors and emotions. In: Romme, M.; Escher, S.; Dillon, J.; Corstens, D.; Morris, M. Living with voices: 50 stories of recovery. 
Birmingham City University: PCCS Revista Crítica Jurídica, Cidade do Books, 2009. p.63-72.

México,v. 19, 2001. pp. 15-31, jul/dez.

SANTO TOMÁS DE AQUINO. ZANELLO, Valeska; MARTINS,

Suma Teológica. Tradução de Alexandre Francisco. O reencontro da clínica com a Correia, 1936. Disponível em: metáfora. Psicologia em Estudo, Maringá, http://alexandriacatolica.blogspot.com.br. v.15, n.1, 2010. pp.189-196.

Acesso em: 12 de mar. de 2017.

SARBIN, Theodore Roy; JUHASZ, Joseph. The historical background of the concept of hallucination. Journal of the history of the behavioral sciences, n. 5, 1967. pp. 339-358, oct.

SMITH, Daniel. Muses, madmen, and prophets: hearing voices and the borders of sanity. New York: Penguin Books, 2008. 254p.

SPINELLI, Miguel. O Daimónion de Sócrates. Revista Hypnos, São Paulo, n. 16, 2006. pp. 32-61, $1^{\circ}$ sem.

TERESA DE ÁVILA. The interior castle or The mansions. London: Thomas Baker, 1921. (Obra original publicada em 1577). em: http://www.documenta-catholica.eu. Acesso em: 23 de jan. de 2017.

VERNANT, Jean-Pierre.; VIDALNAQUET, Pierre. O momento histórico da tragédia na Grécia: algumas condições sociais e psicológicas. In: . Mito $e$ tragédia na Grécia Antiga. São Paulo: Editora Perspectiva, 2011. p.1-5.

WOLKMER, Antônio Carlos. O pensamento político medieval: Santo Agostinho e Santo Tomás de Aquino. 